\title{
Erratum to: An additional tool towards overcoming absence of specificity of carbon nanostructure-based electrochemical sensors - application to estriol and estradiol detection and distinction
}

\author{
Ivana Cesarino $^{1}$ Ivo A. Hümmelgen ${ }^{2}$
}

Published online: 31 July 2015

(C) Springer-Verlag Berlin Heidelberg 2015

Erratum to: J. Solid State Electrochem. (2015)

DOI: 10.1007/s10008-015-2923-7

where $\eta=\alpha^{\prime \prime}+\beta^{\prime \prime}+\gamma^{\prime \prime}+\left\{\left(\alpha^{\prime}-\alpha^{\prime \prime}\right)+\left(\beta^{\prime}-\beta^{\prime \prime}\right)+\left(\gamma^{\prime}-\gamma^{\prime \prime}\right)\right\}[A]_{r}$. The authors apologize for any caused inconvenience.

The authors regret that Eq. (5) of the published article is not correct. The corrected form of Eq. (5) is:

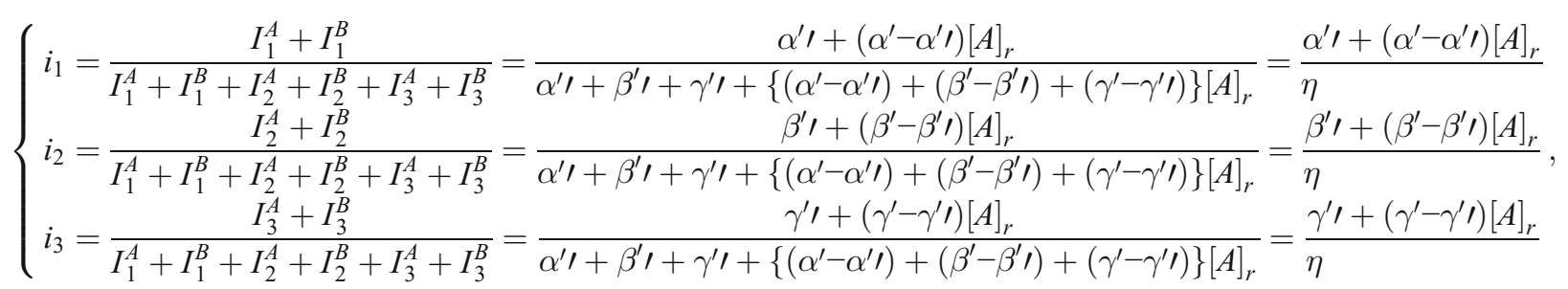

